\title{
Research on bottom anchor supporting technology in Donghai coal mine roadway
}

\author{
Chen Gang ${ }^{1, a}$, Sun Guangyi $i^{1, b}$, Wang Qiong ${ }^{2, c}$ \\ ${ }^{1}$ Heilongjiang Institute of Science and Technology \\ ${ }^{2}$ Haerbin University \\ a26935715@qq.com, bsgy8866@sohu.com, cwangqiong1127@163.com
}

Keywords: floor heave, bottom anchor, mechanical model, simulation, site observation

\begin{abstract}
Floor heave is one of the main characteristics of deep roadway, once it happens, large deformation in the roadway surrounding rock, especially in road way sides, the normal safe production must be influenced seriously. Research of roadway floor heave mechanism, stress field and displacement field, which are influenced by the dynamic pressure caused by coal mining, is still inadequate. The floor heave is discussed by establishing theoretical model and simulating it. At the same time, taking the surrounding rock as an interrelated whole, reducing deformation stress as research purposes, the main means of preventing tunnel floor heave is by the combined support technology of controlling the roadway deformation and reduce surrounding rock stress.
\end{abstract}

\section{Introduction}

No.32 coal of Donghai 12-Auxiliary tunnel in Jixi bureau is one of important coals, with 1160m buried depth, 2.6m height, and 3.8m width.

\section{Control of roadway floor heave}

In order to control the floor heave effectively, a lot of research have been done by domestic and foreign scholars, much floor heave control technology is obtained, which can be sum up as two aspects: the one method is to prevent the floor heave, using measures such method as strengthening, pressure relief, combination and reinforcing roadway side, angle to reduce the floor heave to a permit range. The other method is to remove floor leave rocks, but this method has some malpractice, such as wasting manpower and resources, increasing repair cost, affecting the normal production and safety seriously. So the low-cost, convenient-construction reinforcing floor method is used to increase the floor bearing capacity.

\section{Mechanical model of tunnel floor heave}

When mining depth reaches a certain value, the rock will show the soft rock properties, with no consideration of rock expansion because of meeting water, the surrounding rock in big depth can be considered as loose body, with the property of low tensile, shear and bending strength. In above case, the law of floor heave can be explained by Rankine earth pressure theory. In order to facilitate the calculation of roadway floor, assuming both sides may be destroyed under uniform distributed load $p$ and $\mathrm{q}$, the load is shown in figure 1.

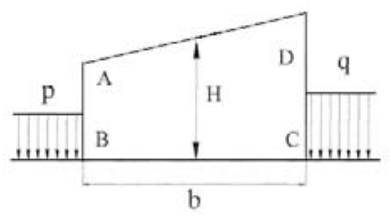

\section{figure 1 diagram of load on tunnel floor}

Right floor is analyzed, the calculation diagram is shown in figure 2. Under pressure of P, CIJ regional rock is in active plastic stress state, while the MCJ region is in passive stress state. If the 
surround rock upward stress exceeds ultimate strength, the floor MC (or BG) will be damaged, and floor heave happens.

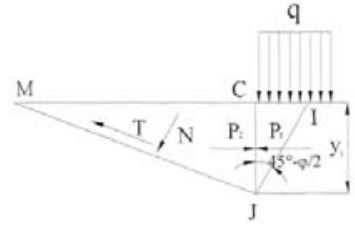

figure 2 botom failure diagram under $q$

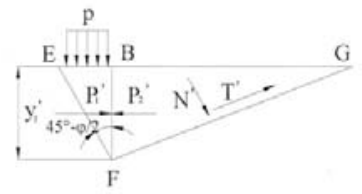

figure 3 botom failure diagram under $p$

Calculation diagram of left floor heave is shown in figure3. It is on the assumption that pressure $q$ is bigger than pressure $p$, the floor two sides will generate sliding body, which slips to tunnel internal room, resulting in floor heave and floor pressure. Based on the size of slip body, there are several kinds of floor heave forms, which are shown in figure 4.

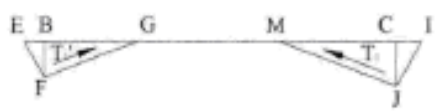

(a) floor heave about angle area

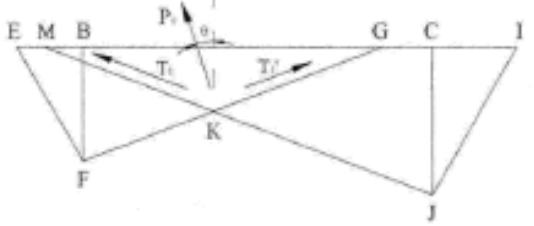

(c) floor heave in quasi full section

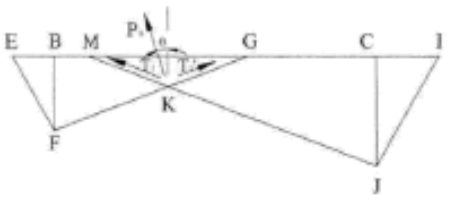

(b) floor heave in local area

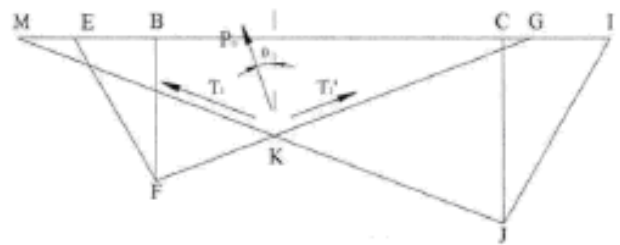

(d) floor heave in full section

figure 4 destruction form caused by floor heave

Floor heave in figure a mainly at tunnel sides, and bottom pressure is also distributed at this area, the bottom pressure value is effective sliding force of both sides. Slip body MGK, shown in figure b, heaves in the compression action of both sides, and the bottom pressure distributes uniformly along the central floor MG . Block MGK in figure c heaves upward under the pressure of two sides, and bottom compression distributes uniformly along BG. Block MGK in figure c heaves upward under the pressure of two sides, bottom compression distributes along all width.

When property of surrounding rock is good, the three methods to reduce bottom compression and floor heave are shown as follows: (1) Controlling floor heave actively. It is this method that uses long enough bolt or cable to penetrate the active destruction region, and consolidate it to the stable layer. This method not only can hinder active fracture zone extruded downwards movement, but also increase the angle of internal friction, reduce the active pressure and floor heave. (2) Controlling floor heave passively. It is this method that uses long enough bolt to consolidate loose rock of bottom to stable layer. This method can prevent upward movement, increase internal friction angle of passive zone, reduce effective slider sliding force and bottom pressure. (3) Consolidating loose rock. It is this method that uses grouting to reinforce tunnel rock, that is, actually increased the strength of surrounding rock. In practical work, the three should be combined to control the floor heave.

\section{Simulation study on anchor timbering effect in deep roadway}

Surrounding rock deformation and failure effect is simulated by RFPA, and stress curve, displacement curve is shown as figure 5 and figure6.
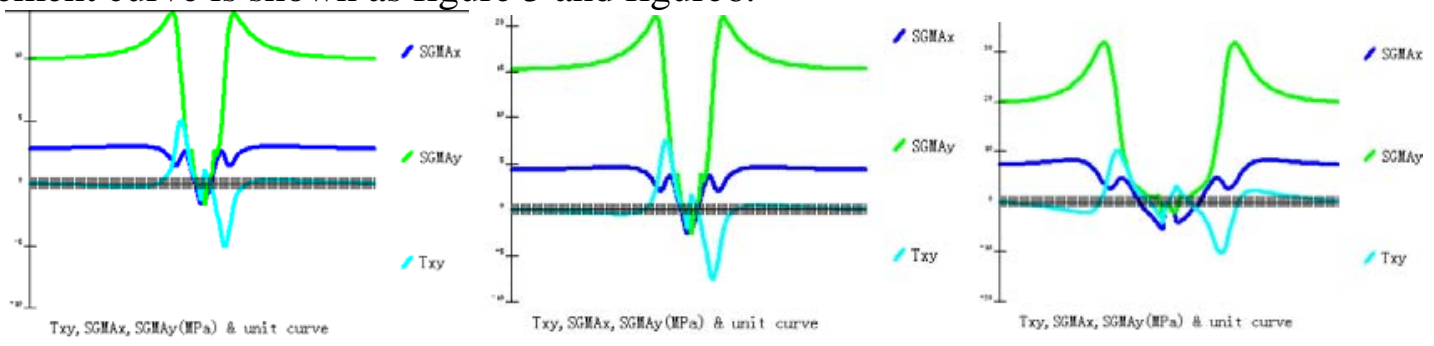
figure 5 stress ditribution of step 20,step30 and step 35 with no bottom anchor

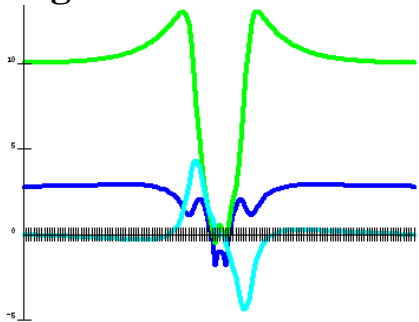

Txy, SGMAx, SGMAy(MPa) \& unit curve

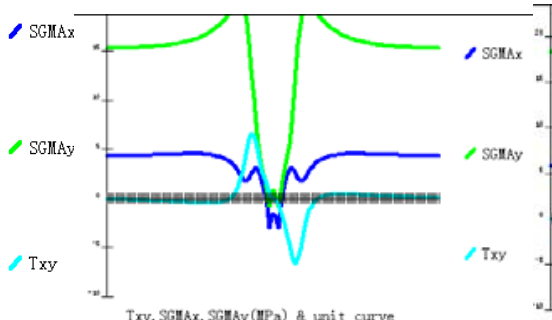

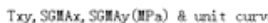

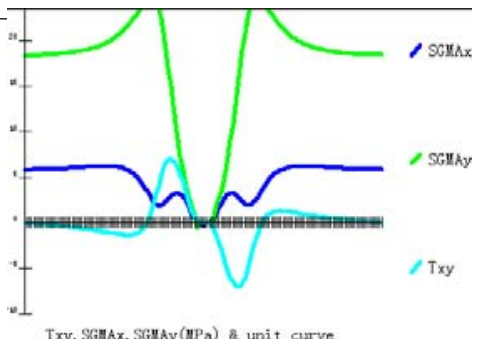

XXy, SGHAx, SGHAy(HPa) a unit curve

figure 6 stress ditribution of step 20,step30 and step 35 with adding bottom anchor

Through the simulation, stresses concentrate almost at tunnel edge, and in this area, there are big horizontal stress, vertical stress and displacement. The stress maximum is at intersection of bottom and sides. The whole floor is at a state of big displacement. Floor heave form is seem as mechanization $d$ in figure 5. In order to control the floor heave, support methods are used, from the simulation, shown in figure7, roadway bolts support effetely.

\section{Site observation}

The experimental section is observed, in order to accurately get the experimental section of floor stability. The roadway section and reinforcement form are shown in figure 7 , and floor stability of experimental section is shown in Figure 8.

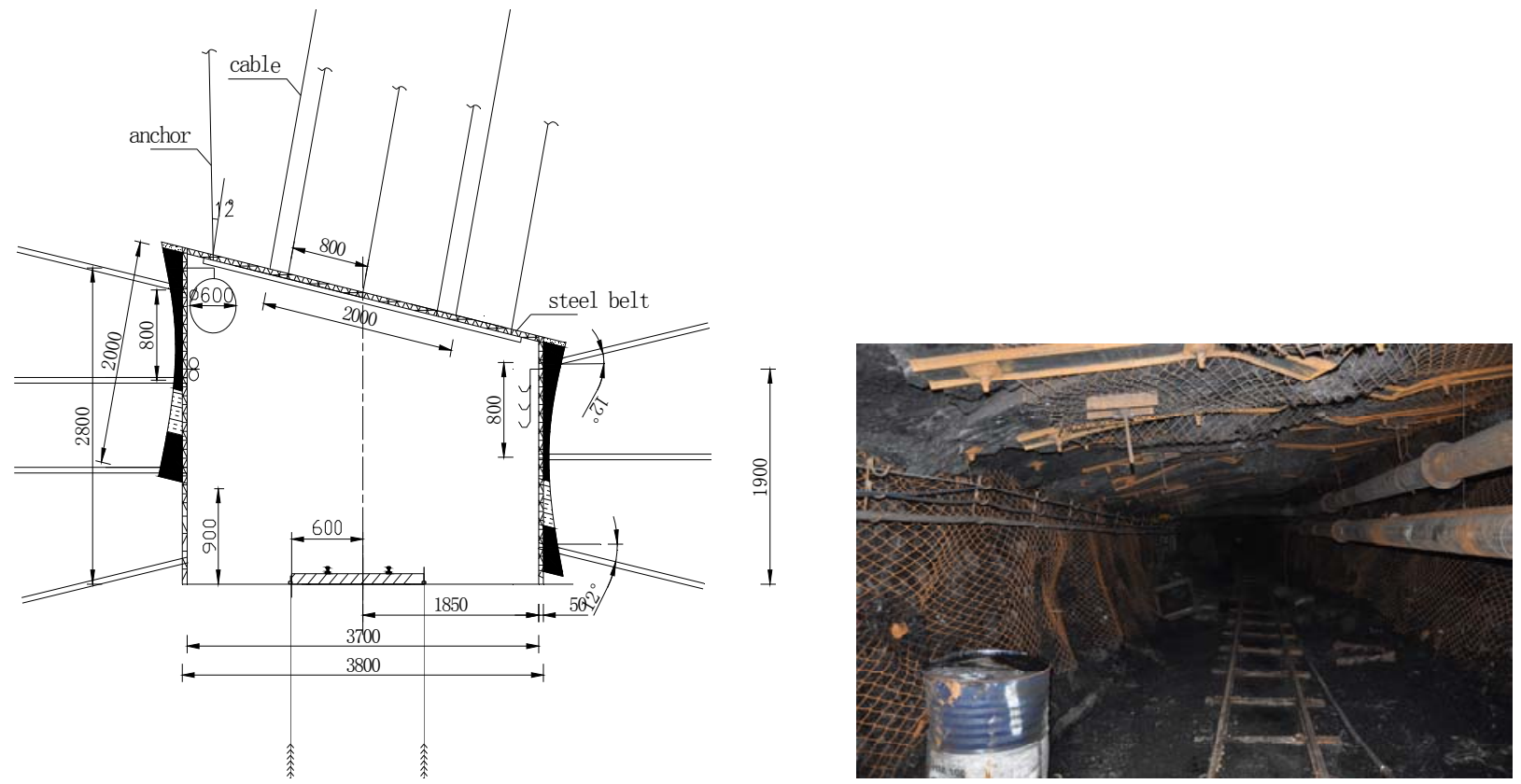

figure 7 tunnel section and support distribution figure 8 bottom stability in experimental area

Site experiment lasted 5 months, a lot of useful data are got. Through the collation, displacement of each observation point across tunnel are got and shown as figure9.

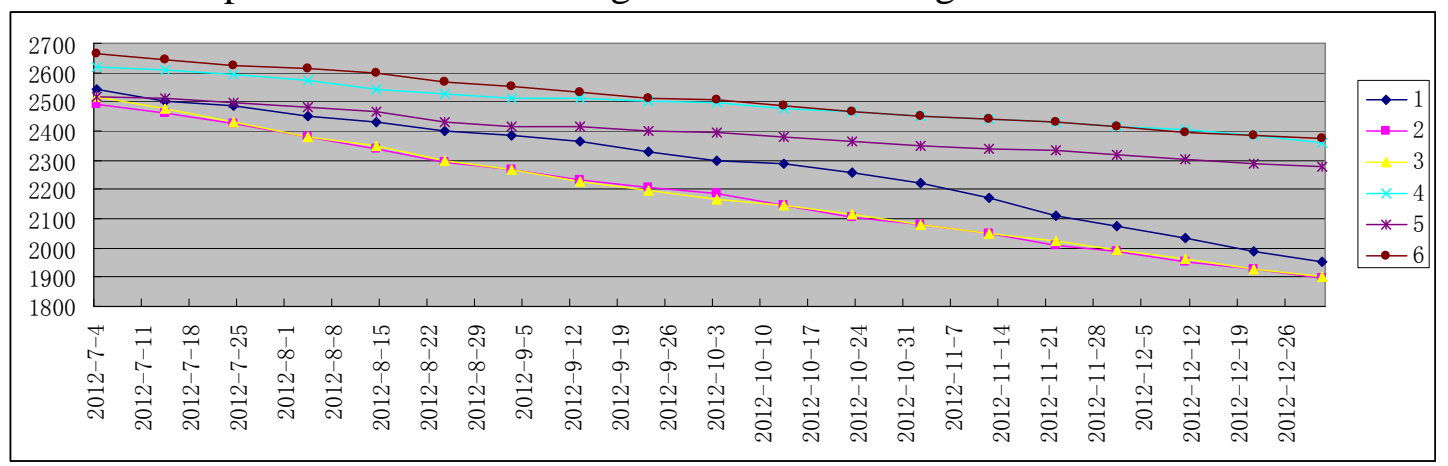

figure 9 comparation between roof displacement and floor displacement in two conditions 
In figure9, curve1, curve 2 and curve 3 represent displacement of tunnel roof and floor with no bottom anchor, and curve4, curve 5 and curve 6 represent displacement of tunnel roof and floor with adding bottom anchor. Through the observing data, in case of adding bottom anchor and no bottom anchor, the displacement of roadway roof and floor is similar at first. But with time going, the displacement in some section of no bottom anchor is bigger than that in adding bottom anchor. The displacement in adding bottom anchor is only about $1 / 2$ of that in no bottom anchor until observing deadline, and the displacement is to stable.

\section{Conclusion}

Floor heave mechanism in deep tunnel is studied. Mechanical model of floor heave failure is established, numerical method is used to simulate floor heave development. Through simulation and analysis, some useful conclusions are shown as following:

1) The main reason of floor heave in Donghai 12-Auxiliary tunnel is the high earth stress. Dilation, expiation and slip toward to internal tunnel under the action of sides' vertical compression.

2) Bottom anchor can control floor heave effectively, having a very good application prospect.

3) Bottom anchor method has such advantage as simple construction, low cost, and is easy to be accepted.

\section{Acknowledgments}

This research was supported by Grants No. 51074068 from national natural science foundation of china.

\section{Reference}

[1] Li Bentao,Yuan Qi, Research on Deep and Soft Rock Roadway Supporting Technology [J], Coal Mining Technology, 2007(03).

[2] Liu Yuanlin, Qin Yumin, Yang jinglin, harness method of deep soft rock tunnel heave[J], Mine Construction Technology, 2009(01).

[3] Zhao Chongguo, Three Level Control Technology of Floor Heave in Deep Tunnel[J], Coal Science and Technology Magazine, 2010(01).

[4] Ye Mingliang, Influence of Underground Mining on District Roadways and Calculation of Surrounding Rock Stress [J], Coal Technology of Northeast China, 1998.2(l):30-34.

[5] Zhang Jinliang,Yan Shuai, Application of Thick Coal Seam Mining-induced Drift Supporting Technology [J], coal, 2009(06).

[6] Wang Weijun, Hou Zhoujong, Study on Mechanical Principle and Control Technique of Floor Heave in Roadway Driven along next Goaf [J], Chinese Journal of Rock Mechanics and Engineering, 2004(01)

[7] Jiang Fuxin, Coal Compression and Rock Layer Control[M], Coal Industry Publish, 2004.8: 234-238. 